Article

\title{
Antibacterial Activity and Toxicity of Analogs of Scorpion Venom IsCT Peptides
}

\author{
Roberto de la Salud Bea *, Adam F. Petraglia, Michael R. Ascuitto and Quentin M. Buck \\ Department of Chemistry, Rhodes College, 2000 North Parkway, Memphis, TN 38112, USA; \\ adam.petraglia@gmail.com (A.F.P.); mrascuitto@yahoo.com (M.R.A.); Quentin.Buck@bcm.edu (Q.M.B.) \\ * Correspondence: saludbear@rhodes.edu; Tel.: +1-901-8433-649; Fax: +1-901-8433-497
}

Academic Editor: Naresh Kumar

Received: 6 June 2017; Accepted: 26 June 2017; Published: 28 June 2017

\begin{abstract}
Seven analogs of the natural, $\alpha$-helix peptides IsCT1 and IsCT2-found in the venom of scorpion Opithancatus Madagascariensis-have been synthesized and tested to compare their antibacterial and hemolytic activity against natural peptides. In general, results show that increasing hydrophobicity by substituting positions 5 and 9 of the sequences with alanine, valine, and leucine, enhances antibacterial activity. However, this also increases hemolytic activity. The analog with an increased net positive charge from +1 to +3 produces moderate bacterial growth inhibition but also has high hemolytic activity. On the other hand, the analog with a negative net charge (-1) has low antibacterial properties but also no cytotoxicity under the tested conditions, a similar result was found for five of the seven studied analogs.
\end{abstract}

Keywords: antimicrobial peptides; $\alpha$-Helix; amphipathic; hemolysis

\section{Introduction}

In recent years, pathogenic organisms have developed resistance to highly utilized drugs, not only for humans, but also for animals [1]. This increasingly renders traditional antibiotic treatments ineffective. Thus, it is necessary to find new treatments for these resistant diseases [2-4]. A new interest in natural products has produced the discovery of non-traditional compounds, such as venoms, with valuable medicinal properties used as anticoagulants, treatment for diabetes, or analgesics $[5,6]$. Antimicrobial peptides are typically short length peptides (5 to 100 amino acids) found in blood, immune system cell secretions, and venoms of animals or plants [7-9]. These peptides can adopt several secondary structures, including $\alpha$-helices and beta sheets with or without cysteines and disulfide bonds. However, all of them have in common the presence of a hydrophobic side with hydrophobic amino acids and a hydrophilic side containing cationic amino acids. Although these peptides can have different lengths and structures, their amphipathic properties are essential for their mechanism of action. The most commonly accepted mechanism suggests the peptides bind the cell surface create distortions that are followed by the formation of pores or the complete destruction of the cell membrane and the release of plasma contents [10]. New studies have also proposed mechanisms involving direct interaction with intracellular targets [11].

Venoms are complex mixtures of components used by animals and plants for defense or to attack enemies or prey. IsCT1 (ILGKIWEGIKSLF) and IsCT2 (IFGAIWNGIKSLF) (Isalo CytoToxic) are two peptides found by Dai in the venom of scorpion Opithancatus madagascariensis [12]. These two 13 amino acid long peptides have an amidated C-terminus and form an $\alpha$-helix secondary structure with amphipathic properties. Studies show significant antimicrobial activity against Gram-positive and Gram-negative bacteria but, as expected by their poisonous origin, they also have high hemolytic activity that prevents clinical practicality [13]. Nevertheless, several analogs with substituted residues in defined positions of the sequence show promising antimicrobial activity with moderate or minimal 
toxicity [14]. These compounds have the mechanism of action of other amphipathic peptides. However, in a recent paper, Ghosh also suggests that some IsCT analogs may have activity without disrupting the cell membrane by penetrating it and inhibiting bacterial macromolecule biosynthesis, such as nucleic acids and proteins [15].

In our group, we have synthesized seven analogs of the two natural IsCT1 and IsCT2 peptides and tested their antibacterial and toxic (hemolytic) activities. Modifications have been made on both the hydrophobic and the hydrophilic sides of the helix. On the hydrophobic side (positions 5 and 9 of the sequence) we have substituted alanine, valine, and leucine in order to test how an increase in amino acid size, and in this way, through peptide volume and hydrophobicity, affect antibacterial activity. On the hydrophilic side (positions 7 and 10 of the sequence) we have synthesized a lysine substituted analog, IsCT1K7 [16] to introduce positive charges and also a glutamic acid substituted analog, IsCT1E7 to introduce negative charges under experimental conditions.

\section{Results}

\subsection{Peptide Design IsCT}

Seven peptides analogs were synthesized using two naturally found 13-residue, amphipathic peptides IsCT1 and IsCT2 as reference models (Table 1). These natural peptides have a free $\mathrm{N}$-terminal and an amidated C-terminus with no cysteine (thus, with no disulfide bonds) and adopt an $\alpha$-helix conformation in hydrophobic environments.

To test the influence of increasing residue size and hydrophobicity in the structure and activity of the analogs, positions 5 and 9 on the hydrophobic side of the helix (Figure 1) were systematically substituted with the hydrophobic amino acids alanine, valine, and leucine. For IsCT1 K7 analog, the substitution of a lysine on position 5 increases total charge from +1 to +3 . Although IsCT1K7 was first synthesized by Kim [16], we used it in this work in order to compare its activity under our experimental conditions against the other analogs and to specifically test the influence of positive and negative charged amino acids on overall activity. Thus, we also made substitutions of the same hydrophilic positions (7 and 10) with glutamic acid to switch the total charge to -1 for peptide IsCTE7. The original natural peptides were also synthesized for reference and comparison.

Based on the model for the $\alpha$-helix structure for these peptides, it can be seen in these star projections (Figure 1) for IsCT1 and IsCT2 that positions 5 and 9 fall on a hydrophobic section of the peptide while positions 7 and 10 are on the hydrophilic side.

Table 1. Amino acid sequences, molecular masses, and HPLC retention times of IsCT peptides.

\begin{tabular}{|c|c|c|c|c|c|}
\hline \multirow[t]{2}{*}{ Peptide } & \multirow[t]{2}{*}{ Amino Acid Sequence ${ }^{a}$} & \multicolumn{2}{|c|}{ Molecular Mass } & \multirow{2}{*}{$\begin{array}{l}\text { HPLC Retention } \\
\text { Times } \\
\text { (min.) }\end{array}$} & \multirow[t]{2}{*}{ Net Charge } \\
\hline & & Calculated & Observed & & \\
\hline IsCT1 & ILGKIWEGIKSLF-NH $_{2}$ & 1502.9 & 1504.2 & 22.7 & +1 \\
\hline IsCT2 & IFGAIWNGIKSLF-NH & 1464.8 & 1466.0 & 20.5 & +1 \\
\hline IsCT1A1 & ILGKAWEGAKSLF-NH 2 & 1418.7 & 1419.8 & 17.5 & +1 \\
\hline IsCT1V1 & ILGKVWEGVKSLF-NH 2 & 1474.8 & 1476.0 & 19.0 & +1 \\
\hline IsCT1L1 & ILGKLWEGLKSLF-NH $_{2}$ & 1502.9 & 1503.8 & 20.6 & +1 \\
\hline IsCT1K7 & ILGKIWKGIKSLF-NH $_{2}$ & 1501.9 & 1502.1 & 20.0 & +3 \\
\hline IsCT1E7 & ILGKIWEGIESLF-NH & 1503.8 & 1505.0 & 22.0 & -1 \\
\hline IsCT2A1 & ILGAAWNGAKSLF-NH $_{2}$ & 1380.6 & 1380.8 & 19.3 & +1 \\
\hline IsCT2V1 & ILGAVWNGVKSLF-NH ${ }_{2}$ & 1436.7 & 1437.1 & 20.5 & +1 \\
\hline
\end{tabular}

${ }^{a}$ Bold letters indicate the substituted amino acids. 


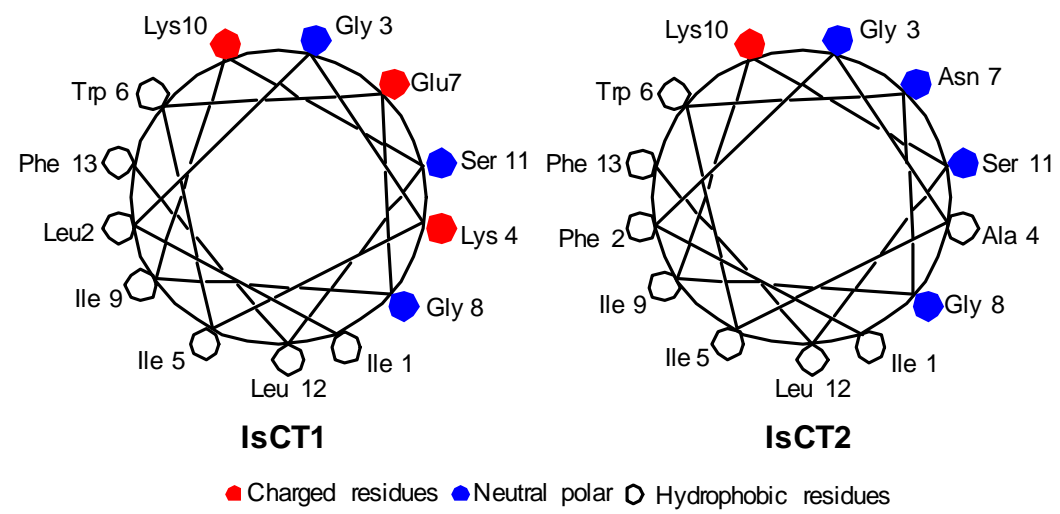

Figure 1. Schiffer and Edmunson alpha helix wheel projection of IsCT1 and IsCT2 peptides.

\subsection{Secondary Structure}

Our main goal was not to study full mechanism of action or physical interaction of our peptides with cell membranes. However, to have an idea of what type of secondary structure our peptides were able to form, we dissolved them in water and in a solution of the helix promoter trifluoroethanol (TFE) in water. Circular Dichroism (CD) analysis shows peptides with a random structure in water (Table 2 and Figure S1). On the other hand, all peptides show a helical structure in the hydrophobic environment 50\% TFE in water. Although some peptides were tested in $70 \%$ TFE, the results were not different to 50\% TFE. In general, our IsCT peptide analogs show a helical structure, though lower to equally substituted analogs of similar BmKn peptides, also extracted from scorpion venoms [17]. Interestingly, the two alanine analogs (IsCT1A1 and 2A1) had the lowest helical structure despite the reported $\alpha$-helix stabilizing properties of this amino acid [18].

Table 2. $\alpha$-Helical content of IsCT peptides in water and 50\% TFE.

\begin{tabular}{ccccc}
\hline \multirow{2}{*}{ Peptides } & \multicolumn{3}{c}{ Water } & \multicolumn{2}{c}{$\mathbf{5 0 \%}$ TFE } \\
\cline { 2 - 5 } & {$[\theta]_{\mathbf{2 2 2}}$} & \% Helix & {$[\theta]_{\mathbf{2 2 2}}$} & \% Helix \\
\hline IsCT1 & -2046.57 & Random & $-11,484.85$ & 30.2 \\
IsCT2 & -1242.43 & Random & -9006.83 & 22.0 \\
IsCT1A1 & -1408.15 & Random & -6602.05 & 14.1 \\
IsCT1V1 & -1722.88 & Random & -8803.10 & 21.3 \\
IsCT1L1 & -1855.45 & Random & $-10,500.37$ & 27.0 \\
IsCT1K7 & -1520.41 & Random & -9533.00 & 23.8 \\
IsCT1E7 & -2561.86 & 1.0 & $-12,183.56$ & 33.0 \\
IsCT2A1 & -89.92 & Random & -3633.66 & 4.3 \\
IsCT2V1 & -793.14 & Random & -6586.81 & 14.0 \\
\hline
\end{tabular}

This was also observed for BmKn peptides [19]. It is also apparent that an increase in size of the substituted amino acid (from alanine to valine to leucine), increases the percent helix. It is likely that hydrophobicity is the major factor for this observation and the total increase in peptide volume does not interfere with the formation of a more organized secondary structure. Also, the glutamic acid substituted analog has the highest percent helix, suggesting that altering the net charge from +1 to -1 does not perturb the peptide structure either.

\subsection{Antimicrobial Activities}

Antimicrobial activities were determined by standard broth dilution against two Gram-positive and three Gram-negative bacteria. In general, the MICs seem to be higher than the concentrations tested in our experiments (Table 3). Only Staphylococcus aureus and Escherichia coli seem to be inhibited 
with both natural peptides but also by the leucine substituted analogue, IsCT1L1, at concentrations lower than $25 \mu \mathrm{g} / \mathrm{mL}$. The lysine substituted analogue (IsCT1K7) with two extra positive charges (+3) seems to be more effective than other analogs with $a+1$ charge. The negatively charged $(-1)$ peptide (IsCT1E7), although having the highest percentage $\alpha$-helix structure, does not show the expected inhibition, with higher than $100 \mu \mathrm{g} / \mathrm{mL}$ for all tested bacteria. Curiously, some peptides—such as IsCT1V1, IsCT1E7, or even natural IsCT1—when tested with Bacillus cereus show significant bacteria growth inhibition at concentrations lower than $10 \mu \mathrm{g} / \mathrm{mL}$. However, increasing the concentration does not increase inhibition and bacterial growth reaches a plateau or increases slightly (Figure S2).

Table 3. MIC ( $\mu \mathrm{g} / \mathrm{mL})$. Antibacterial activity of IsCT1 and IsCT2 analogs.

\begin{tabular}{cccccc}
\hline \multicolumn{5}{c}{ MIC $(\mu \mathrm{g} / \mathrm{mL})$} \\
\hline S. aureus & B. cereus & S. typhimurium & E. aerogenes & E. coli \\
\hline IsCT1 & 50 & $>100$ & 100 & $>100$ & 50 \\
IsCT2 & 50 & 100 & 100 & $>100$ & 50 \\
IsCT1A1 & $>100$ & $>100$ & $>100$ & $>100$ & $>100$ \\
IsCT1V1 & $>100$ & $>100$ & $>100$ & $>100$ & $>100$ \\
IsCT1L1 & 50 & $>100$ & 100 & $>100$ & 50 \\
IsCT1K7 & 100 & $>100$ & 100 & $>100$ & $>100$ \\
IsCT1E7 & $>100$ & $>100$ & $>100$ & $>100$ & $>100$ \\
IsCT2A1 & $>100$ & $>100$ & $>100$ & $>100$ & $>100$ \\
IsCT2V1 & $>100$ & $>100$ & $>100$ & & $>100$ \\
\hline
\end{tabular}

\subsection{Hemolytic Activity}

The original peptides, along with the the leucine and lysine substituted analogs (IsCT1L1 and IsCT1K7), show the highest hemolytic activity. The other peptide analogs have negligible toxicity against erythrocytes under the conditions and concentrations tested, particularly the analog with a negative charge (IsCT1E7), which has no toxicity at all (Figure 2).

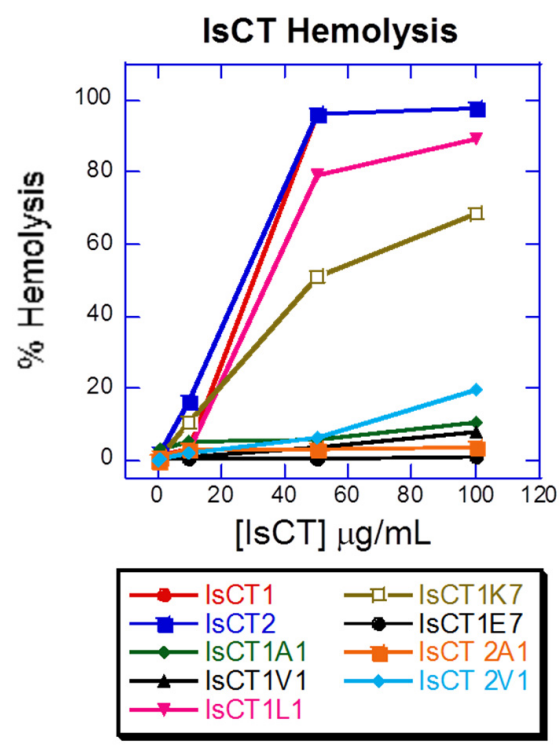

Figure 2. Hemolytic activity of peptide analogs.

\section{Discussion}

Although recent studies propose novel mechanisms of action for antimicrobial peptides inside the bacterial cytoplasm [15], the most commonly accepted mechanism implies the binding of 
the peptides to the cell membrane surface which creates a mechanical disruption followed by the total destruction of the cell membranes [10]. The typical features for antimicrobial peptides are the formation of a well-defined secondary structure, usually a $\alpha$-helix or a $\beta$-sheet, and the presence of both hydrophobic and hydrophilic regions creating an amphiphilic (also called amphipathic) nature necessary for the proposed mechanism of action of these antimicrobial peptides [20]. Though a more in-depth study of the structure these peptides and their interaction with the bacteria cell membranes will be necessary to fully correlate structure with activity, preliminary results with our synthetic seven analogs of the natural IsCT1 and IsCT2 peptides show they are able to form secondary $\alpha$-helix structures. As mentioned, according to these results, it seems that an increase in size of the substituted amino acid (from alanine to valine to leucine) increases the percent helix, probably due to an increase in hydrophobicity with the introduction of more hydrophobic amino acids. The larger size of the amino acids seems not to affect helix structure. Changes in peptide net charge from +3 (IsCT1K7) to -1 (IsCT1E7) do not perturb the helical structure either.

Studies of bacterial inhibition carried out by Dai with IsCT1 and IsCT2 natural peptides show a range of MICs of 1 to $5 \mu \mathrm{g} / \mathrm{mL}$ for different strains of $S$. aureus and 10 to $25 \mu \mathrm{g} / \mathrm{mL}$ for two strains of Bacillus [21]. For Gram-negative bacteria, they show 5 to $120 \mu \mathrm{g} / \mathrm{mL}$ for two strains of E. coli but 100 or more than $200 \mu \mathrm{g} / \mathrm{mL}$ for other strains of Gram-negative bacteria (Pseudomonas aeruginosa and Proteus mirabilis). Bacterial inhibition studies by Kim with IsCT show MICs of $6 \mu \mathrm{g} / \mathrm{mL}$ for E. coli and $3 \mu \mathrm{g} / \mathrm{mL}$ for $S$. aureus and, for the IsCT1K7 analog, the reported concentrations are 3 and $1.5 \mu \mathrm{g} / \mathrm{mL}$, respectively. Our results show MICs higher than the tested peptide concentrations of $100 \mu \mathrm{g} / \mathrm{mL}$ for all the tested bacteria except for S. aureus and E. coli. For the leucine substituted IsCTL1 analog, growth of S. aureus was inhibited at around $20-25 \mu \mathrm{g} / \mathrm{mL}$ while E. coli was inhibited at 15 and $25 \mu \mathrm{g} / \mathrm{mL}$. As mentioned above, some analogs such as valine (IsCT1V1) or glutamic acid (IsCT1E7) substituted peptides show that bacteria growth is inhibited at low concentrations $(10 \mu \mathrm{g} / \mathrm{mL})$ followed by a leveling off or even an apparent increase in bacterial growth at higher concentrations. This phenomenon has been observed previously and a possible explanation is the formation of peptide aggregates [19].

It is also clear that the peptides that show higher bacteria growth inhibition-the natural IsCT1 and IsCT2, as well as the analogs IsCT1L1 and IsCT1K7-show the highest hemolytic activity. However other analogs, especially IsCT1E7 which has a net negative charge, though they do not appear to have a significant bacterial growth inhibition, do not have any apparent citotoxicity either under the tested concentrations and conditions. This result can be used for future design of similar antimicrobial peptides.

\section{Materials and Methods}

\subsection{Reagents}

All Fmoc-protected amino acids, the activating reagent 2-(1H-benzotriazol-1-yl)-1,1,3,3tetramethyluronium hexafluorophosphate (HBTU), and Rink-Amide AM Resin (200-400 nm mesh) used for the manual solid phase peptide synthesis were purchased from Nova-Biochem. Dimethyl formamide (DMF), acetonitrile, diisopropyl ethyl amine, trifluoro acetic acid, and bacteria broth were purchased from Fisher Scientific to the purest quality and used without further purification. Bacteria were supplied by Rhodes College Department of Biology collection.

\subsection{Peptide Synthesis and Purification}

The synthesis and purification of the peptides was carried out as described previously [19]. Briefly, peptides were synthesized using manual solid-phase peptide synthesis with fluorenyloxycarbonyl (Fmoc) chemistry. Purification was carried out by reversed-phase high-performance liquid chromatography (RP-HPLC) with an acetonitrile/water gradient and $0.08 \%$ trifluoro acetic acid. Retention times range from 17 to $23 \mathrm{~min}$ (Table 1). Peptides were characterized by mass spectrometry. All peptides were dissolved in water to a concentration of $2 \mathrm{mg} / \mathrm{mL}$ (milligrams/milliliter) to form 
stock solutions and stored at $-20^{\circ} \mathrm{C}$. Peptide solutions used for all assays were formed by diluting aliquots of stock solutions to the required $\mu \mathrm{g} / \mathrm{mL}$ concentrations.

\subsection{Characterization of Helical Structure}

The mean residue ellipticities of the peptides were determined in water and in the presence of $\alpha$-helix inducing solvent, 2,2,2-trifluoroethanol (TFE) at 50\% in water by circular dichroism (CD). The mean residue molar ellipticity, $[\theta]$, is given in $\mathrm{deg} \cdot \mathrm{cm}^{2} \cdot \mathrm{dmol}^{-1}$ and was calculated as described previously [19]. Values are the result of three independent experiments.

\subsection{Bacteria Strains}

Two Gram-positive bacteria: Staphylococcus aureus (ATCC\# 29213) and Bacillus cereus (ATCC\# 11778); and three Gram-negative bacteria: Salmonella typhimurium (ATCC\# 14028), Enterobacter aerogenes (ATCC\# 13048), and Escherichia coli (ATCC\# 25922) were tested.

\subsection{Measurement of Antibacterial Activity}

Activity was determined by the standard liquid dilution method described previously [19]. All results are the average of three independent experiments. Briefly, cells were grown overnight at $37^{\circ} \mathrm{C}$ in Luria Bertani broth and diluted in the same medium for assays. Bacteria were added to serial dilutions of the peptides (final concentrations of $1,10,50$, and $100 \mu \mathrm{g} / \mathrm{mL}$ ) and incubated at $37^{\circ} \mathrm{C}$ for $24 \mathrm{~h}$. Cell growth was measured by UV absorbance at $600 \mathrm{~nm}$. For each bacterium, a solution containing no peptide (concentration $0 \mu \mathrm{g} / \mathrm{mL}$ ) was processed under identical conditions and used as control for $100 \%$ bacterial growth. MICs were obtained from interpolation of $0 \%$ bacterial growth from plots. Results are the average of three independent experiments.

\subsection{Measurement of Hemolytic Activity}

Hemolytic activity was carried out as described previously [19]. Briefly, serial concentrations of peptides (final concentrations of 0 as blank, 1, 10,50, and $100 \mu \mathrm{g} / \mathrm{mL}$ ) were added to $1 \%$ human erythrocytes in $1 \times$ PBS buffer. The cell suspensions were incubated at $37^{\circ} \mathrm{C}$ for $1 \mathrm{~h}$ and then centrifuged to remove unlysed erythrocytes. Released hemoglobin was determined spectrophotometrically at $416 \mathrm{~nm}$. The control for $100 \%$ release of hemoglobin was a sample of $1 \%$ erythrocyte incubated in PBS with $1 \%$ TritonX-100. Results are the average of two independent experiments.

\section{Conclusions}

Our study with analogs of IsCT peptides found in scorpion venoms has shown that natural or wild type peptides have the highest bacterial growth inhibition compared to their synthetic analogs here studied. Of these, leucine substituted analog IsCT1L1, shows higher antibacterial activity but also toxicity similar to the wild type peptides. An increase in the net positive charge in IsCT1K7 or the net negative charge in IsCT1E7 does not improve the inhibition much. However, the fact that analog IsCT1E7 along with others have no apparent cytotoxicity for the concentrations tested is a promising starting point to design future potential antibacterial peptides.

Supplementary Materials: The following are available online at www.mdpi.com/2079-6382/6/3/13/s1, Figure S1: Circular Dichroism (CD) plots for IsCT peptides in water and 50\% TFE, Figure S2: Bacteria inhibition with peptide analogues.

Acknowledgments: The financial support for this study was provided by Rhodes College startup funds DOC144 (Fund 112072) and 2013 and 2014 Faculty Development Endowment summer grants DOC731 (Fund 112366). Special thanks to Prof. Laura Luque de Johnson (Rhodes College) for providing with bacteria strains. Also, special thanks to Daniel Baker and Abigail Parrill—both at the University of Memphis—for the use of their MS and CD instruments. 
Author Contributions: Roberto de la Salud Bea conceived and designed the experiments; performed all the peptide characterization, antibacterial, and toxicity experiments; and wrote the manuscript. Authors Adam F. Petraglia, Michael R. Ascuitto, and Quentin M. Buck (all now already graduated from Rhodes College) performed the full synthesis of the peptides studied in this work.

Conflicts of Interest: The authors declare no conflict of interest. The founding sponsors had no role in the design of the study; in the collection, analyses, or interpretation of data; in the writing of the manuscript, or in the decision to publish the results.

\section{References}

1. Nhung, N.T.; Cuong, N.V.; Thwaites, G.; Carrique-Mas, J. Antimicrobial usage and antimicrobial resistance in animal production in Southeast Asia: A review. Antibiotics 2016, 5, 37. [CrossRef] [PubMed]

2. Adegoke, A.A.; Faleye, A.C.; Singh, G.; Stenstrom, T.A. Antibiotic resistant superbugs: Assessment of the interrelationship of occurrence in clinical settings and environmental niches. Molecules 2017, $22,29$. [CrossRef] [PubMed]

3. Chellat, M.F.; Raguz, L.; Riedl, R. Targeting antibiotic resistance. Angew. Chem. Int. Ed. 2016, 55, 6600-6626. [CrossRef] [PubMed]

4. Perez-Jorge, C.; Gomez-Barrena, E.; Horcajada, J.-P.; Puig-Verdie, L.; Esteban, J. Drug treatments for prosthetic joint infections in the era of multidrug resistance. Expert Opin. Pharmacother. 2016, 17, 1233-1246. [CrossRef] [PubMed]

5. Samy, R.P.; Satyanarayanajois, S.; Franco, O.L.; Stiles, B.G.; Gopalakrishnakone, P. Animal venoms as natural sources of antimicrobials. In Antibiotics: Current Innovations and Future Trends; Sánchez, S., Demain, A.L., Eds.; Caister Academic Press: Haverhill, UK, 2015; pp. 229-247. [CrossRef]

6. Harvey, A.L. Toxins and drug discovery. Toxicon 2014, 92, 193-200. [CrossRef] [PubMed]

7. Dang, L.; van Damme, E.J.M. Toxic proteins in plants. Phytochemistry 2015, 117, 51-64. [CrossRef] [PubMed]

8. Wang, G.; Mishra, B.; Lau, K.; Lushnikova, T.; Golla, R.; Wang, X. Antimicrobial peptides in 2014. Pharmaceuticals 2015, 8, 123-150. [CrossRef] [PubMed]

9. Harrison, P.L.; Abdel-Rahman, M.A.; Miller, K.; Strong, P.N. Antimicrobial peptides from scorpion venoms. Toxicon 2014, 88, 115-137. [CrossRef] [PubMed]

10. Lam, K.L.H.; Wang, H.; Siaw, T.A.; Chapman, M.R.; Waring, A.J.; Kindt, J.T.; Lee, K.Y.C. Mechanism of structural transformations induced by antimicrobial peptides in lipid membranes. Biochim. Biophys. Acta Biomembr. 2012, 1818, 194-204. [CrossRef] [PubMed]

11. Taniguchi, M.; Ochiai, A.; Takahashi, K.; Nakamichi, S.-I.; Nomoto, T.; Saitoh, E.; Kato, T.; Tanaka, T. Antimicrobial activity and mechanism of action of a novel cationic alpha-helical octadecapeptide derived from alpha-amylase of rice. Biopolymers 2015, 104, 73-83. [CrossRef] [PubMed]

12. Dai, L.; Yasuda, A.; Naoki, H.; Corzo, G.; Andriantsiferana, M.; Nakajima, T. IsCT, a novel cytotoxic linear peptide from scorpion opisthacanthus madagascariensis. Biochem. Biophys. Res. Commun. 2001, 286, 820-825. [CrossRef] [PubMed]

13. Belokoneva, O.S.; Villegas, E.; Corzo, G.; Dai, L.; Nakajima, T. The hemolytic activity of six arachnid cationic peptides is affected by the phosphatidylcholine-to-sphingomyelin ratio in lipid bilayers. Biochim. Biophys. Acta Biomembr. 2003, 1617, 22-30. [CrossRef]

14. Lim, S.S.; Kim, Y.; Park, Y.; Kim, J.I.; Park, I.-S.; Hahm, K.-S.; Shin, S.Y. The role of the central L- or D-pro residue on structure and mode of action of a cell-selective alpha-helical IsCT-derived antimicrobial peptide. Biochem. Biophys. Res. Commun. 2005, 334, 1329-1335. [CrossRef] [PubMed]

15. Tripathi, J.K.; Kathuria, M.; Kumar, A.; Mitra, K.; Ghosh, J.K. An unprecedented alteration in mode of action of IsCT resulting its translocation into bacterial cytoplasm and inhibition of macromolecular syntheses. Sci. Rep. 2015, 5, 9127. [CrossRef] [PubMed]

16. Lee, K.; Shin, S.Y.; Kim, K.; Lim, S.S.; Hahm, K.-S.; Kim, Y. Antibiotic activity and structural analysis of the scorpion-derived antimicrobial peptide IsCT and its analogs. Biochem. Biophys. Res. Commun. 2004, 323, 712-719. [CrossRef] [PubMed]

17. De la Salud Bea, R.; Petraglia, A.F.; de Johnson, L.E.L. Synthesis, antimicrobial activity and toxicity of analogs of the scorpion venom BmKn peptides. Toxicon 2015, 101, 79-84. [CrossRef] 
18. Lopez-Llano, J.; Campos, L.A.; Sancho, J. Alpha-helix stabilization by alanine relative to glycine: Roles of polar and apolar solvent exposures and of backbone entropy. Proteins Struct. Funct. Bioinform. 2006, 64, 769-778. [CrossRef] [PubMed]

19. De la Salud Bea, R.; Ascuitto, M.R.; de Johnson, L.E.L. Synthesis of analogs of peptides from Buthus martensii scorpion venom with potential antibiotic activity. Peptides 2015, 68, 228-232. [CrossRef] [PubMed]

20. Huang, Y.; He, L.; Li, G.; Zhai, N.; Jiang, H.; Chen, Y. Role of helicity of alpha-helical antimicrobial peptides to improve specificity. Protein Cell 2014, 5, 631-642. [CrossRef] [PubMed]

21. Dai, L.; Corzo, G.; Naoki, H.; Andriantsiferana, M.; Nakajima, T. Purification, structure-function analysis, and molecular characterization of novel linear peptides from scorpion Opisthacanthus madagascariensis. Biochem. Biophys. Res. Commun. 2002, 293, 1514-1522. [CrossRef]

2017 by the authors. Licensee MDPI, Basel, Switzerland. This article is an open access article distributed under the terms and conditions of the Creative Commons Attribution (CC BY) license (http:/ / creativecommons.org/licenses/by/4.0/). 